\title{
Terra-firma forme dermatosis: Report of three cases
}

\section{Terra-firma forme dermatoz: Üç olgu bildirimi}

๑ Tasleem Arif

\author{
Ellahi Medicare Clinic, Srinagar, Kashmir, India
}

\begin{abstract}
Terra-firma forme dermatosis (TFFD), also known as Duncan's dirty dermatosis, is characterized by "dirt-like" brown-grey cutaneous patches and plaques. Abnormal and delayed keratinization has been implicated in its pathogenesis. The disorder is not well known by dermatologists even though affected patients present with typical dirt-like lesions. TFFD can be easily diagnosed and treated with $70 \%$ isopropyl alcohol. It is important to recognize this benign dermatologic entity because it can be easily confused with many other dermatological conditions. Hence, in order to avoid unnecessary referrals, laboratory investigations, skin biopsies, and medications, a trial of wiping the skin lesion with $70 \%$ isopropyl alcohol pads is suggested whenever the diagnosis of TFFD is considered. In this article, the author is reporting three new cases of TFFD.
\end{abstract}

Keywords: Delayed keratinization, Duncan's dirty dermatosis, Terra-firma forme dermatosis, 70\% isopropyl alcohol

Öz

Duncan'ın kirli dermatozu olarak da bilinen Terra-firma forme dermatoz (TFFD), kir benzeri kahverengi gri renkli plaklar ile karakterize bir klinik tablodur. Anormal ve gecikmiş keratinizasyon patogenezinde rol oynar. Hastalıkta, tipik kir benzeri lezyonlar olsada, ayıııc tanıda zorlanılabilir. TFFD'nin, \%70 izopropil alkol ile silinerek giderilmesi tanı almasını ve tedavisini sağlar. Bu benign dermatozun tanınması, gereksiz hastane başvurularının, laboratuvar araştırmaları, deri biyopsileri ve ilaç tedavilerinin önüne geçilmesi için önemlidir. Bu yazıda yazar üç yeni TFFD olgusu bildirmektedir.

Anahtar Kelimeler: Gecikmiş keratinizasyon, Duncan'ın kirli dermatozu, Terra-firma forme dermatozis, \%70 izopropil alkol

\section{Introduction}

Terra firma-forme dermatosis (TFFD), also known as Duncan's dirty dermatosis, is an acquired, idiopathic and bizarre dermatological condition that is characterized by asymptomatic, dirt-like, hyperpigmented patches and plaques that cannot be eradicated by routine washing with water and soaps. However, the lesions are easily removed after rubbing with $70 \%$ isopropyl or ethyl alcohol pads thus serving as a diagnostic cum therapeutic test for the condition'. Here in the author reports three cases of TFFD where the rubbing of skin lesions with 70\% isopropyl alcohol pads served both as a diagnostic and therapeutic modality.

\section{Case Reports}

\section{Case 1}

A 14-year-old boy presented with a 2 month history of asymptomatic multiple muddy brownish colored skin eruption on his neck and upper back. The patient was healthy, non-atopic and was not receiving any medication. Despite having good hygiene, including showers and washing with medicated soaps like Dettol at least 3 times per week, the patient showed no improvement in the skin lesions. Examination revealed multiple well defined muddy brown hyperpigmented patches with a dirty surface present over neck and upper back (Figure 1a). Potassium hydroxide (KOH)

\footnotetext{
Address for Correspondence/Yazıșma Adresi: Tasleem Arif MD, Ellahi Medicare Clinic, Srinagar, Kashmir, India Phone: +919557480345 E-mail: dr_tasleem_arif@yahoo.com Received/Geliş Tarihi: 30.08.2018 Accepted/Kabul Tarihi: 02.04.2019 ORCID: orcid.org/0000-0002-7965-5194
} 
examination of the skin scrapings didn't show any fungal elements. Given the appearance and distribution of skin lesions, TFFD was considered and swabbing with cotton pads soaked in 70\% isopropyl alcohol was performed that completely removed the lesions, revealing the underlying normal skin (Figure 1b).

\section{Case 2}

A 20-year-old man presented with a 1 1/2-year history of asymptomatic brownish skin lesions over the chest and back. He had tried some "over the counter" topical medications but without any improvement in the skin lesions. His medical and dermatological history was unremarkable. His hygiene was good and was taking showers with soap and water at least 3-4 times per week. Dermatological examination showed multiple well defined muddy- brown hyperpigmented plaques with a dirty surface present over the upper chest near the root of neck and back (Figure 2 a,c) Skin scrapings for $\mathrm{KOH}$ examination didn't reveal any fungal component. With a suspicion of TFFD, swabbing with $70 \%$ isopropyl alcohol pads was performed that completely removed the lesions (Figure $2 \mathrm{~b}, \mathrm{~d}$ ) confirming the diagnosis.

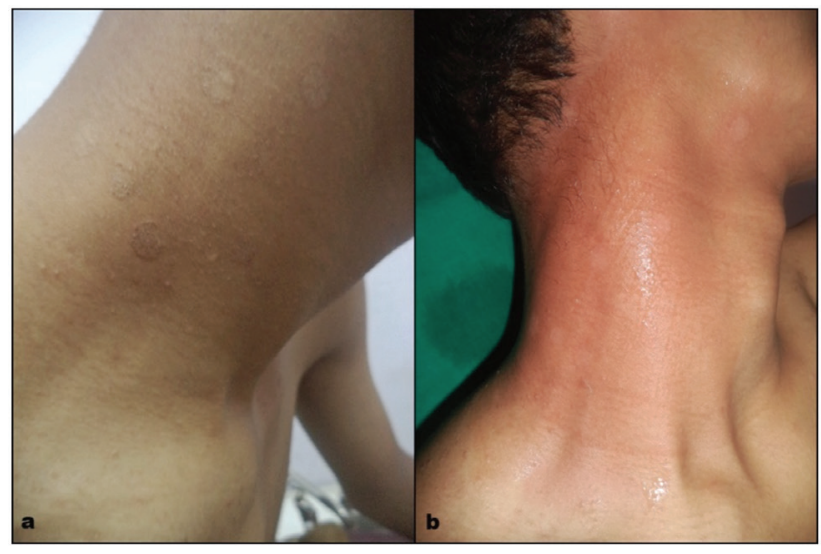

Figure 1. There are multiple well defined muddy brown hyperpigmented plaques with a dirty surface present over neck a) and b) immediate clearance of lesions after swabbing with cotton pads soaked in $70 \%$ isopropyl alcohol

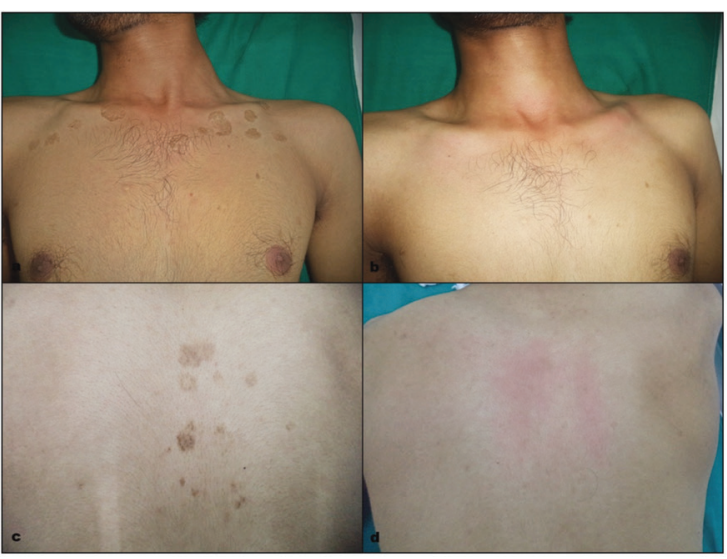

Figure 2. There are multiple well defined muddy-brown hyperpigmented plaques with a dirty surface present over the upper chest a) and back c) and b,d) prompt clearance of lesions after wiping with $70 \%$ isopropyl alcohol

\section{Case 3}

A 16 year old boy presented with one month history of asymptomatic brownish skin lesions on the neck. He had a good hygiene taking showers using routine soap and water at least 3 times a week. His medical and dermatological history was non-contributory. On examination, there were multiple well defined muddy- brown hyperpigmented plaques with a dry dirty surface present over the antero-lateral aspect of neck (Figure 3a). $\mathrm{KOH}$ examination of the skin scrapings was unremarkable. Complete cure was attained (Figue $3 b$ ) by powerful swabbing of the skin with $70 \%$ isopropyl alcohol-soaked gauze pads confirming the diagnosis of TFFD.

\section{Discussion}

The term "TFFD" was first coined by Duncan, Tscben and Knox in 1987 to describe a dermatological condition that is relatively common but usually unrecognized. Hence, it is also called as Duncan's dirty dermatosis². Why this term "TFFD" was used has not been explained by the authors. However, "terra firma" in Latin means "solid land/dirty land". This term is often used to differentiate land from sea. The lesions of TFFD most often resemble dirt, hence the name ${ }^{3}$. TFFD seems to be an under-diagnosed and under-reported dermatological condition with very few published reports in the past two decades.

TFFD affects a wide range of ages (3 months to 72 years), with an equal incidence in both gender. It is mainly seen in children and adults ${ }^{4}$. Similarly all remove the our three patients were lying in the age group 10-20 years. However in the present series, only males were present

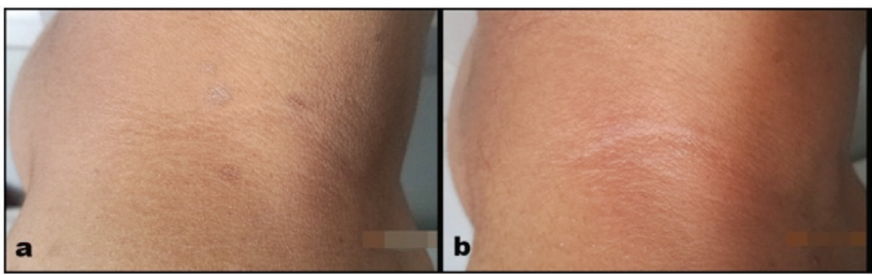

Figure 3. Well defined muddy-brown hyperpigmented plaques with a dry surface present over the antero-lateral aspect of neck a) and b) their immediate clearance after the alcohol wiping test

Table 1. Differential diagnosis of terra-firma forme dermatosis

\begin{tabular}{l}
\hline Confluent and reticulate papillomatosis \\
\hline Acanthosis nigricans \\
\hline Dirty neck syndrome of atopic dermatitis \\
\hline Dermatosis neglecta \\
\hline Epidermal nevi \\
\hline Epidermolytic hyperkeratosis \\
\hline Granular parakeratosis \\
\hline Ichthyosis \\
\hline Idiopathic deciduous skin \\
\hline Seborrheic keratosis \\
\hline Pityriasis versicolor \\
\hline Pseudoacanthosis nigricans \\
\hline Omphalith \\
\hline
\end{tabular}


probably because of a very short series. It is seen in individuals with normal washing habits, which excludes inadequate cleansing as the cause of the lesions, such as those seen in dermatosis neglecta (DN) 5 . TFFD most often presents as asymptomatic brown or dark colored, dirtlike patches and plaques ${ }^{4,6}$. Morphologically, lesions may be verrucous, papillomatous, or reticulate ${ }^{7}$. Sites of affliction include neck, trunk, face, ankles. However unusual sites reported include axilla, scalp, chest, back, umbilical area, lips, pubis, arms and legs. In short, any area of the body can get affected ${ }^{3,6-10}$. Similarly, two of the three patients had lesions on neck and back while chest involvement was seen in one. Some reports have suggested that TFFD has a predilection for concave skin areas and heavier patients which has been confirmed by others ${ }^{11}$. The distribution of lesions in TFFD varies from case to case. It can be localized, generalized, bilateral, or unilateral ${ }^{1,4,5}$. Some authors have reported that TFFD most often presents during the warmer months of the year ${ }^{2}$.

The etiology of TFFD remains unknown. The current knowledge about this entity does not favour a genetic susceptibility or familial inheritance ${ }^{7,12}$. Various researchers have suggested that TFFD is a disorder of abnormal and delayed keratinization in which the incomplete maturation of keratinocytes together with melanin retention and build up and compaction of scales causes the typical dirt-like lesions ${ }^{3,6,7,12}$ Thus pathophysiologically, TFFD can be considered retention, rather than a proliferative hyperkeratosis ${ }^{10}$. Sunlight exposure as a triggering factor has also been reported by some researchers ${ }^{8,12}$. Erkek et al. ${ }^{4}$ reported two cases of TFFD, one with xerosis cutis since childhood and the other with atopic dermatitis. Both of them were applying $10 \%$ urea containing emollients on moist skin after bath while one of them was advised by physicians to bath less frequently and to avoid abrasive sponges and scrubs. She used to take bath twice a week with tepid water without cleansers. The authors concluded that TFFD may arise due to failure to rinse off oily soaps during shower. Additionally, the application of humectants like urea-containing moisturizers on dry or eczematous skin can also be contributory. Remnants of emollients, oily soaps, or cleansers together with pathological scaling in diseased skin may induce keratoplastic or adhesive properties at some areas resulting in accumulation of scales, sebum and dirt and thus preventing normal keratinocyte shedding. Hence, the authors suggested that TFFD is a milder form of DN in which the "neglect" is unintentional or secondary to professional advice.

Biopsies are not routinely performed since the diagnosis is straightforward in most of the cases. The histopathology of TFFD is characterized by epidermal acanthosis with papillomatosis. A prominent lamellar hyperkeratosis with tendency to form compact orthokeratotic whorls along with keratotic material in the valleys between the papillae is considered the hallmark of TFFD $3,4,8$. However, no parakeratosisis is seen. There is no significant inflammatory infiltrate in the dermis ${ }^{4,12}$. Toluidine blue stains show scattered keratin globules throughout the stratum corneum. Other special stains have showed increased melanin content in the compact hyperkeratotic and basal areas of the epidermis (Fontana-Masson) and the occasional yeast spores in the stratum corneum, Malassezia furfur being the most commonly identified yeast (Periodic Acid Schiff) 1,5,6,8. Electron microscopy has shown that there is a disordered and delayed keratinization in TFFD ${ }^{3,5}$.

DN forms an important differential diagnosis and needs to be elaborated here. Etiologically, DN as the term implies results from neglect or inadequate hygiene or poor skin cleansing which may be secondary to various causes like physical disability, psychiatric problem or a neurological deficit while in TFFD hygiene and washing is adequate. Clinically, DN is characterised by cornflake-like brownish scales which are not seen in TFFD. Histopathologically, whorled hyperkeratosis which is a characteristic finding of TFFD is not seen in DN. Therapeutically, there is successful removal of skin lesions with soap and water in DN but not in TFFD. However, 70\% isopropyl alcohol causes effective clearance of lesions in both. Despite these differences, the distinction between DN and TFFD becomes difficult at times and it seems that there exists clinical and histological overlap between the two conditions $3,4,6,7,9,10,13$. Some authors have suggested that the difference between TFFD and DN is arbitrary and TFFD may be a milder form of $\mathrm{DN}^{14}$.

TFFD can simulate many dermatoses (Table 1). Confluent and reticulated papillomatosis (CRP) is a rare dermatosis of unknown etiology mostly affecting young adults. The lesions consist of confluent, brown, flat papules present in a reticulated pattern. Sites of predilection include intermammary, epigastric and interscapular regions but may involve the neck and axillae as well. Histologically, CRP is characterized by hyperkeratosis and papillomatosis with no acanthosis ${ }^{6,15}$. Acanthosis nigricans is characterized by hyperpigmented, velvety plaques in body folds, though involvement of other areas may occur as well. Lesions are typically symmetrical in distribution, usually affecting intertriginous areas. Histology shows hyperkeratosis and irregular spiky papillomatosis ${ }^{6,16}$. Pityriasis versicolor is caused by various species of the genus Malassezia. When pityriasis versicolor clinically presents with hyperpigmented scaly macules, TFFD may be thought in differential diagnosis. The fine bran like scales of the macules of pityriasis versicolor become prominent on stretching the affected skin called as Zireli's sign. Woods light examination of the lesions and direct microscopy for fungal elements confirm the diagnosis ${ }^{17}$. Omphalith refers to a "stone" in the umbilicus. The gradual accumulation of sebum and keratin leads to the formation of a hard stone-like mass. On some occasions it can be associated with ulceration or secondary infection which can be its presenting feature ${ }^{18}$.

Seborrheic keratoses are very common benign tumors that affect most of the older people. Clinically, lesions start as small flat to slightly elevated macules with varying shades of brown color. They can be confused with TFFD at this initial stage of evolution. ${ }^{6}$ Idiopathic deciduous skin has been used to refer periodic/seasonal or continuous shedding of the epidermal layers of the skin without any known cause. There is spontaneous superficial peeling of the skin of the body usually sparing the palms, soles, mucous membrane, and scalp. The peeled skin may resemble dirt which can be hard to clean. This brown peeled keratin may stick to the underlying epidermis and get dried which may confuse it with TFFD. Histopathological examination shows subcorneal separation and bulla formation without acantholysis ${ }^{19}$. Dirty neck syndrome of atopic dermatitis, a peculiar type of hyperpigmentation rarely observed particularly on the neck; in some adolescents and adult patients with chronic atopic dermatitis. This condition has been termed as "dirty neck" appearance or "ripple pigmentation of the neck in atopic dermatitis". Clinically, there is a rippled pattern of hyperpigmentation seen particularly on the anterior and lateral aspects of the neck. Amyloid can be detected in the skin biopsy specimens by electron microscopy ${ }^{20}$. 
Intertriginous granular parakeratosis clinically presents with unilateral or bilateral, usually pruritic, erythematous to hyperpigmented papules and plaques mainly involving the intertriginous areas, especially the axillary areas. It commonly affects the middle-aged women. The histopathologic features are characteristic and include hyperparakeratosis with retention of keratohyaline granules in the stratum corneum. In addition, papillomatosis, acanthosis, vascular ectasia and vascular proliferation have been frequently reported ${ }^{21}$.

Epidermal nevi are usually seen at birth or develop in early childhood. They can be flat, tan or brown patches of skin or raised, velvety patches. They frequently follow a pattern along the lines of Blaschko 22 . Ichthyoses represent a large clinically and etiologically heterogeneous group of conditions characterized by generalized scaling of the skin. Defective epidermal desquamation is a feature of some ichthyoses while a prominent inflammatory component occurs in others, usually associated with epidermal hyperproliferation. Some types of ichthyoses like epidermolytic ichthyosis, steroid sulfatase deficiency, icthyosis hystrix, milder forms of lamellar icthyosis, etc can sometimes resemble morphologically to TFFD. However a proper history regarding age of onset, history of associated blistering, erosions, erythroderma, peeling/ exfoliation, collodion membrane and inability of the lesions to get wiped off by alcohol test will easily differentiate these from TFFD ${ }^{23}$.

The treatment of TFFD consists of forceful rubbing with a gauze pad immersed in 70\% isopropyl alcohol or ethyl alcohol which serves as a diagnostic as well as therapeutic modality ${ }^{4,5}$. In none of the above mentioned diseases lesions resolve with wiping test with $70 \%$ isopropyl alcohol or ethyl alcohol. This wiping test with alcohol avoids unnecessary referrals, laboratory investigations, skin biopsies and medications ${ }^{5}$. Apart from this, it provides an immediate therapeutic cure to the patient ${ }^{12}$. After the wiping test, a normal pink colored skin underneath is exposed which is satisfying for the patient ${ }^{6}$. Recurrence is unusual once the skin has been cleared of "dirty" skin lesions. In some cases weekly application of isopropyl alcohol may be advised to maintain resolution or for prophylaxis 4 .

TFFD is believed to be a common but underreported condition. This entity needs to be recognized otherwise it can lead to unnecessary anxiety and futile endocrinological work up. An increased awareness of this entity is essential as the lesions of TFFD simply disappear by rubbing with $70 \%$ alcohol avoiding the need for referrals and investigations. Physicians should be aware of this condition which seems to be more prevalent than reported in literature ${ }^{3,5,8}$.

\section{Conclusion}

TFFD presents as asymptomatic, brown, dirt-like patches and plaques. All the three patients presented with this typical morphology, and their lesions successfully resolved after wiping with 70\% isopropyl alcohol. TFFD may be an underdiagnosed and underreported condition whose awareness is essential among physicians. The author suggests a trial of rubbing the skin lesion with $70 \%$ isopropyl alcohol gauze pads whenever a suspicion of TFFD is considered so as to avoid unnecessary lab tests, skin biopsies, referrals and medications.

\section{Ethics}

Informed Consent: The author certifies that he has obtained all the appropriate patient consent forms. In the form the patients have given their consent for their images and other clinical information to be reported in the journal. The patients understand that their names and initials will not be published and due efforts will be made to conceal their identity.

Peer-review: Externally and internally peer-reviewed.

Financial Disclosure: The authors declared that this study received no financial support.

\section{References}

1. Cemil BC, Canpolat F, Ataş H, Şaşmaz R: Terra firma-forme dermatosis. J Turk Acad Dermatol 2014;8:1484c3.

2. Duncan WC, Tschen JA, Knox JM: Terra firma-forme dermatosis. Arch Dermatol 1987;123:567-9.

3. O'Brien TJ, Hall AP: Terra firma-forme dermatosis. Australas J Dermatol 1997;38:163-4.

4. Erkek E, Sahin S, Çetin ED, Sezer E: Terra firma-forme dermatosis. Indian J Dermatol Venereol Leprol 2012;78:358-60.

5. Kurtipek GS, Akyürek FT, Arzu Ataseven A, Kocaoğlu C: Terra firma-forme dermatosis in childhood: Two cases. J Turk Acad Dermatol 2015;9:1591c2.

6. Akkash L, Badran D, Al-Omari AQ: Terra firma-forme dermatosi. Case series and review of the literature. J Dtsch Dermatol Ges 2009;7:102-7.

7. Guarneri C, Cannavò SP: Is this skin diseased, or is it just dirty? JAAPA 2009;22:17.

8. Browning J, Rosen T: Terra firma-forme dermatosis revisited. Dermatol Online J 2005;11:15.

9. Berk DR: Terra firma-forme dermatosis: A retrospective review of 31 cases. Pediatr Dermatol 2011;29:297-300.

10. Berk DR, Bruckner AL: Terra firma-forme dermatosis in a 4-month-old girl. Pediatr Dermatol 2011;28:79-81.

11. Greywal T, Cohen PR: Terra firma-forme dermatosis: A report of ten individuals with Duncan's dirty dermatosis and literature review. Dermatol Pract Concept 2015;5:8

12. Guarneri C, Guarneri F, Cannavò SP: Terra firma-forme dermatosis. Int J Dermatol 2008;47:482-4.

13. Perez-Rodriguez IM, Munoz-Garza FZ, Ocampo-Candiani J: An unusually se-vere case of dermatosis neglecta: A diagnostic challenge. Case Rep Dermatol 2014;6:194-9.

14. Ashique KT, Kaliyadan F, Goyal T: Terra firma-forme dermatosis: report of a series of 11 cases and a brief review of the literature. Int J Dermatol 2016;55:769-74

15. Löwenstein $M$, Metzler $G$, Röcken $M$, Schaller $M$ : Erfolgreiche minozyklintherapie der papillomatosis confluens et reticularis GougerotCarteaud. J Dtsch Dermatol Ges 2006;4:556-8.

16. Schwartz RA: Acanthosis nigricans. J Am Acad Dermatol 1994;31:1-19.

17. Arif T: Acral pityriasis versicolor - A rare clinical presentation. Our Dermatol Online 2015;6:196-7.

18. Swanson SL, Woosley JT, Fleischer AB, Crosby DL: Umbilical mass. Omphalith. Arch Dermatol 1992;128:1267-70.

19. Panja SK, Sengupta S: Idiopathic deciduous skin. Int J Dermatol. 1982;21:262-4.

20. Humphreys F, Spencer J, Mclaren K, Tidman MJ: An histological and ultrastructural study of the 'dirty neck' appearance in atopic eczema. Clin Exp Dermatol 1996;21:17-9.

21. Martín JM, Pinazo I, Molina I, Monteagudo C, Villalón G, Jordá E: Parakeratosis. Inter J Dermatol 2008;47:707-8.

22. Moss $\mathrm{C}$, Shahidullah $\mathrm{H}$. Naevi and other developmental defects. In: Burns T, Breathnach S, Cox N, Griffi ths C. Eds. Rook's Textbook of Dermatology. Wiley-Blackwell, U.K, 8th edition 2010;1:18.4-18.8.

23. Richard G, Ringpfeil F. Ichthyoses, Erythrokeratodermas and related disorders. In: Jean L Bolognia, Joseph L Jorizzo, Julie V Schaffer, editors. Dermatology. $3^{\text {rd }}$ ed. USA: Elsevier Saunders; 2012;1:837-70. 